\title{
Inhibitory effects of tetrandrine on epidermal growth factor-induced invasion and migration in HT29 human colorectal adenocarcinoma cells
}

\author{
CHI-TING HORNG ${ }^{1,2^{*}}$, JAI-SING YANG ${ }^{3 *}$, JO-HUA CHIANG ${ }^{4}$, CHI-CHENG LU ${ }^{5}$, \\ CHIU-FANG LEE ${ }^{6}$, NI-NA CHIANG ${ }^{6}$ and FU-AN CHEN ${ }^{7}$
}

\author{
${ }^{1}$ Medical Education Center, Kaohsiung Armed Forces General Hospital, Kaohsiung 802; \\ ${ }^{2}$ Institute of Biochemistry and Biotechnology, Chung Shan Medical University and Chung Shan Medical University Hospital, \\ Taichung 402; ${ }^{3}$ Department of Medical Research, China Medical University Hospital, China Medical University, Taichung 404; \\ ${ }^{4}$ Department of Nursing, Chung-Jen Junior College of Nursing, Health Sciences and Management, Chiayi 622; \\ ${ }^{5}$ School of Nutrition and Health Sciences, Taipei Medical University, Taipei 110; \\ ${ }^{6}$ Kaohsiung Veterans General Hospital Pingtung Branch, Pingtung 912; ${ }^{7}$ Department of Pharmacy and \\ Graduate Institute of Pharmaceutical Technology, Tajen University, Pingtung 907, Taiwan, R.O.C.
}

Received December 23, 2014; Accepted October 19, 2015

DOI: $10.3892 / \mathrm{mmr} .2015 .4635$

\begin{abstract}
Tetrandrine has been shown to reduce cancer cell proliferation and to inhibit metastatic effects in multiple cancer models in vitro and in vivo. However, the effects of tetrandrine on the underlying mechanism of HT29 human colorectal adenocarcinoma cell metastasis remain to be fully elucidated. The aim of the present study was focused on tetrandrine-treated HT29 cells following epidermal growth factor (EGF) treatment, and Transwell, gelatin zymography, gene expression and immunoblotting assays were performed to investigate metastatic effects in vitro. Tetrandrine was observed to dose-dependently inhibit EGF-induced HT29 cell invasion and migration, however, no effect on cell viability occurred following exposure to tetradrine between 0.5 and $2 \mu \mathrm{M}$. Tetrandrine treatment inhibited the enzymatic activity of matrix metalloprotease (MMP)-2 and MMP-9 in a concentration-dependent manner. The present study also found a reduction in the mRNA expression levels of MMP-2 and MMP-9 in the tetrandrine-treated HT29 cells. Tetrandrine also suppressed the phosphorylation of EGF receptor (EGFR) and its downstream pathway, including phosphoinositide-dependent kinase 1, phosphatidylinositol
\end{abstract}

Correspondence to: Professor Fu-An Chen, Department of Pharmacy and Graduate Institute of Pharmaceutical Technology, Tajen University, 20 Weixin Road, Yanpu, Pingtung 90741, Taiwan, R.O.C.

E-mail: fachen.tajen@yahoo.com.tw

*Contributed equally

Key words: tetrandrine, epidermal growth factor receptor, metastasis, matrix metalloprotease-2/-9, HT29 colorectal adenocarcinoma cells 3-kinase and phosphorylated AKT, suppressing the gene expression of MMP-2 and MMP-9. Furthermore, tetrandrine triggered mitogen-activated protein kinase signaling through the suppressing the activation of phosphorylated extracellular signal-regulated protein kinase. These data suggested that targeting EGFR signaling and its downstream molecules contributed to the inhibition of EGF-induced HT29 cell metastasis caused by tetrandrine, eventually leading to a reduction in the mRNA and gelatinase activities of MMP-2 and MMP-9, respectively.

\section{Introduction}

Epidermal growth factor receptor (EGFR) is a member of the ErbB family of receptor tyrosine kinases (1), and EGFR activation by ligand binding stimulates multiple signals, including phosphatidylinositol 3-kinase (PI3K)/AKT, mitogen-activated protein kinases (MAPKs) and nuclear factor- $\kappa \mathrm{B}$ pathways, ultimately resulting in cellular proliferation, survival, angiogenesis invasion and metastasis $(2,3)$. Abnormal protein activity and/or expression levels of EGFR have been correlated with the etiology of several types of human cancer, including colorectal cancer $(4,5)$, non-small cell lung cancer $(6,7)$, breast cancer $(8,9)$, head and neck squamous cell carcinoma $(10,11)$, pancreatic cancer (12) and brain cancer (13). EGFR-targeted therapy has been validated in human colorectal cancer (14), and the chemotherapeutics include pharmacological agents, including cetuximab (Erbitux), which is an EGFR inhibitor (15). EGFR acts to bind an EGFR-selective ligand activated by epidermal growth factor (EGF), transforming growth factor- $\alpha$, amphiregulin or neuregulin, finally leading to cell proliferation, invasion and the inhibition of apoptosis (15-17).

Tetrandrine is a bisbenzylisoquinoline alkaloid, which is isolated from the dried root of Stephania tetrandra of the 
Menispermaceae family $(18,19)$. Tetrandrine has been shown to have broad pharmacological actions (20-22). Several reports have indicated that tetrandrine presents potent anticancer effects on multiple cancer cells in vitro (23-29). Tetrandrine retards Wnt/ $\beta$-catenin signaling and inhibits tumor growth of HCT116 human colorectal cancer (24). Furthermore, the apoptosis of cells in human hepatocellular carcinoma caused by tetrandrine is mediated through the production of reactive oxygen species and the repression of AKT activity (30). Our previous study revealed that tetrandrine induces apoptotic and autophagic cell death in SAS human oral cancer cells (31). Wu et al (32) demonstrated that tetrandrine inhibits cell proliferation, invasion and migration by suppressing the levels of A disintegrin/metalloprotease 17, phosphorylated (p)-EGFR and p-AKT in U87 glioblastoma cells. Therefore, evidence suggests that the suppression of EGFR-PI3K/AKT signaling may contribute to the tetrandrine-induced anticancer activities of inhibition of cell migration and invasion. In the present study, it was demonstrated that tetrandrine inhibited EGF-induced HT29 cell invasion and migration through stimulating the phosphorylation of EGFR, sequentially inactivating the PI3K/AKT cascade, repressing MAPK/extracellular signal-regulated protein kinase (ERK)-mediated signaling and reducing MMP-2 and MMP-9 signals.

\section{Materials and methods}

Chemicals and reagents. In the present study, tetrandrine, EGF and 3-(4,5-dimethyl-2-thiazolyl)-2,5-diphenyl-2H-tetrazolium bromide (MTT) were purchased from Sigma-Aldrich (St. Louis, MO, USA). Dulbecco's modified Eagle's medium (DMEM), fetal bovine serum (FBS), penicillin-streptomycin and trypsin-EDTA were purchased from Gibco (Thermo Fisher Scientific, Inc., Waltham, MA, USA). Anti-p-EGFR (Y845) (2231; 1:1,000), anti-p-EGFR (Y992) (2235; 1:1,000), anti-p-EGFR (Y1068) (2234; 1:1,000), anti-p-phosphoinositide-dependent kinase-1 (PDK1; 3031; 1:1,000), anti-p-PI3K (4228; 1:1,000), anti-p-AKT (S308) (13038; 1:1,000), anti-p-AKT (S473) (4060; 1:1,000), anti-p-ERK (Thr202/Tyr204) (4370; 1:1,000), anti-p-c-Jun N-terminal kinase (JNK; Thr183/Tyr185) (4668; 1:1,000) and anti-p-p38 (Thr180/Tyr182) $(4511 ; 1: 1,000)$ antibodies were purchased from Cell Signaling Technology, Inc. (Danvers, MA, USA). Antibodies against EGFR (sc-03, 1:500), PI3K (sc-423, 1:500), AKT (sc-8312, 1:500), ERK (sc-135900, 1:500), JNK (sc-571, 1:500), p38 (sc-7972, 1:500) and $\beta$-actin (sc-1616, 1:5,000), as well as horseradish peroxidase (HRP)-conjugated secondary antibodies (goat anti-mouse IgG-HRP, sc-2031, 1:10,000; donkey anti-goat IgG-HRP, sc-2033, 1:10,000; and goat anti-rabbit IgG-HRP, sc-2030, 1:10,000) were purchased from Santa Cruz Biotechnology, Inc. (Santa Cruz, CA, USA).

Cell culture. The HT29 human colorectal adenocarcinoma cell line was cultured in DMEM supplemented with $10 \%$ FBS, $100 \mathrm{U} / \mathrm{ml}$ penicillin and $100 \mu \mathrm{g} / \mathrm{ml}$ streptomycin, and incubated in a humidified incubator with $5 \% \mathrm{CO}_{2}$ at $37^{\circ} \mathrm{C} \mathrm{(33).}$

Cell invasion assay. The membrane of each Transwell insert was coated with Matrigel (BD BioCoat BD Matrigel Invasion Chamber; BD Biosciences, Bedford, MA, USA), according to the manufacturer's protocol. The HT29 cells $\left(2 \times 10^{4}\right)$ were seeded onto the upper chamber of the insert in $0.5 \mathrm{ml}$ complete DMEM per Transwell, containing $100 \mathrm{ng} / \mathrm{ml}$ EGF and either $0.5,1$ or $2 \mu \mathrm{M}$ of tetrandrine for $48 \mathrm{~h}$ at $37^{\circ} \mathrm{C}$. The number of invaded cells was analyzed, as previously described (34).

Cell migration assay. The HT29 cells $\left(2 \times 10^{4}\right)$ were seeded into a Transwell insert (BD Biosciences) and incubated with $100 \mathrm{ng} / \mathrm{m}$ EGF and either $0.5,1$ or $2 \mu \mathrm{M}$ of tetrandrine for $48 \mathrm{~h}$ at $37^{\circ} \mathrm{C}$. The number of migrated cells were counted, as described previously by Lu et al (35).

Determination of cell viability using an MTT assay. The HT29 cells $\left(2 \times 10^{4}\right)$ were seeded into the 96 -well plate and were incubated with EGF $(100 \mathrm{ng} / \mathrm{ml})$ and tetrandrine $(0$, $0.5,1$ or $2 \mu \mathrm{M})$. Following incubation for $48 \mathrm{~h}$ at $37^{\circ} \mathrm{C}$, MTT solution $(0.5 \mathrm{mg} / \mathrm{ml})$ was added for an additional $4 \mathrm{~h}$, and the formazan crystals were dissolved by $200 \mu \mathrm{l}$ of dimethyl sulfoxide (Sigma-Aldrich), as described previously (35). The cytotoxicity was determined as previously described (35), with the value of the untreated control sample set as $100 \%$.

Gelatin zymography assay. The HT29 cells $\left(1 \times 10^{5}\right)$ were seeded into a 12-well plate and were exposed to EGF $(100 \mathrm{ng} / \mathrm{ml})$ and various concentrations of tetrandrine $(0,0.5$, 1 or $2 \mu \mathrm{M}$ ) for $48 \mathrm{~h}$ at $37^{\circ} \mathrm{C}$. The conditioned media were collected, and the samples were separated by electrophoresis on an $8 \%$ SDS-polyacrylamide gel with $0.1 \%$ gelatin (Sigma-Aldrich). Subsequently, the gel was incubated in zymogen developing buffer (Sigma-Aldrich), containing $50 \mathrm{mM}$ Tris (pH 7.5), $200 \mathrm{mM} \mathrm{NaCl}, 5 \mathrm{mM} \mathrm{CaCl}_{2}, 1 \mu \mathrm{M}$ $\mathrm{ZnCl}_{2}$ and $0.02 \%$ Brij-35, overnight at $37^{\circ} \mathrm{C}$. The bands corresponding to activity were stained with $0.5 \%$ Coomassie Brilliant blue G-250 (Bio-Rad Laboratories, Inc., Hercules, CA, USA), and the band of gelatinolytic activity was determined using NIH Image J software, version 1.47 (National Institutes of Health, Bethesda, MA, USA), as described previously $(35,36)$.

Reverse transcription quantitative polymerase chain reaction $(R T-q P C R)$ analysis. The HT29 cells $\left(1 \times 10^{7}\right.$ cells in a $75 \mathrm{~cm}^{2}$-flask) were exposed to $0.5,1$ and $2 \mu \mathrm{M}$ of tetrandrine and EGF (100 ng/ml) for $48 \mathrm{~h}$ at $37^{\circ} \mathrm{C}$ prior to total RNA being extracted using a Qiagen RNeasy Mini kit (Qiagen, Valencia, CA, USA). cDNAs were synthesized from each RNA sample, as previously reported $(37,38)$. Subsequent qPCR for each sample was performed using an Applied Biosystems 7300 Real-Time PCR system (Applied Biosystems; Thermo Fisher Scientific, Inc., Waltham, MA, USA) according to the manufacturer's instructions. The cDNAs were mixed with 2X SYBR Green PCR Master mix (Applied Biosystems; Thermo Fisher Scientific, Inc.) and the following primers, according to the manufacturer's protocol (Sigma-Aldrich): MMP-2, forward 5'-CCCCAGACAGGTGATCTTGAC-3' and reverse 5'-GCTTGCGAGGGAAGAAGTTG-3'; MMP-9, forward 5'-CGCTGGGCTTAGATCATTCC-3' and reverse 5'-AGGTTGGATACATCACTGCATTAGG-3'; and GAPDH, forward 5'-ACACCCACTCCTCCACCTTT-3' and reverse TAGCCAAATTCGTTGTCATACC-3'. Each transcript was calculated relative to the housekeeping gene, GAPDH. 
Immunoblotting analysis. The HT29 cells cells (1x10 ${ }^{7}$ cells in a $75 \mathrm{~cm}^{2}$-flask) were treated with EGF (100 $\left.\mathrm{ng} / \mathrm{ml}\right)$ and exposed to $0.5,1$ and $2 \mu \mathrm{M}$ of tetrandrine for $48 \mathrm{~h}$ at $37^{\circ} \mathrm{C}$. Following treatment, the whole cell lysate was collected, and immunoblotting was performed to determine the protein expression levels, as detailed by Chen et al (36). The protein signals were detected using an Immobilon Western Chemiluminescent HRP Substrate kit (Merck Millipore, Billerica, MA, USA) and Bio-MAX MR X-ray film (Eastman Kodak, Rochester, NY, USA), as previously described $(37,38)$.

Statistical analysis. All data are presented as the mean \pm standard deviation. One-way analysis of variance followed by Student's t-test using SPSS software, version 12.0 (SPSS, Inc., Chicago, IL, USA) was used to compare the differences. $\mathrm{P}<0.05$ was considered to indicate a statistically significant difference.

\section{Results}

Tetrandrine inhibits EGF-induced HT29 cell invasion and migration. To determine the effects of tetrandrine on EGF-induced HT29 cells, the abilities of cell invasion and migration was investigated. EGF induction increased the invasion of the HT29 cells, when compared with the untreated control cells (basal), and treatment of the EGF-induced HT29 cells with tetrandrine decreased cell invasion in a concentration-dependent manner (Fig. 1A). In addition, EGF stimulated HT29 cell migration, whereas tetrandrine decreased EGF-induced migration of the HT29 cells in a concentration-dependent manner (Fig. 1B).

Exposure to low concentrations of tetrandrine has no effect on the viability of EGF-induced HT29 cells. To determine whether the inhibited invasion and migration of EGF-induced HT29 cells following exposure to tetrandrine was the result of cytotoxic effects, the present study assessed HT29 cell viability following tetrandrine exposure. The EGF-induced HT29 cells were exposed to various concentrations $(0,0.5,1$ and $2 \mu \mathrm{M})$ of tetrandrine. The results demonstrated that tetrandrine at $0.5-2 \mu \mathrm{M}$ was not cytotoxic towards the EGF-induced HT29 cells (Fig. 2).

Tetrandrine inhibits the enzymatic activities of MMP-2 and MMP-9 in EGF-induced HT29 cells. It has been documented that MMP-2 (gelatinase A) and MMP-9 (gelatinase B) are detected in the invasion and metastasis of colorectal cancer (39), which is closely associated with the malignant potential of tumor invasion and migration (40). Therefore, in the present study, EGF-induced HT29 cells were treated with or without tetrandrine $(0.5,1$ and $2 \mu \mathrm{M})$ and the enzymatic activities of MMP-2/-9 were assessed. Treatment of the EGF-induced cells with tetrandrine reduced the gelatinase activity of MMP-2 (Fig. 3A) and MMP-9 (Fig. 3B), and these effects were dose-dependent.

Tetrandrine reduces the gene expression levels of MMP-2 and MMP-9 in EGF-induced HT29 cells. The present study further investigated whether the suppression of MMP-2 and MMP-9 occurred at the transcriptional level. Prior to EGF induction, the cells were incubated with or without $0.5,1$ and
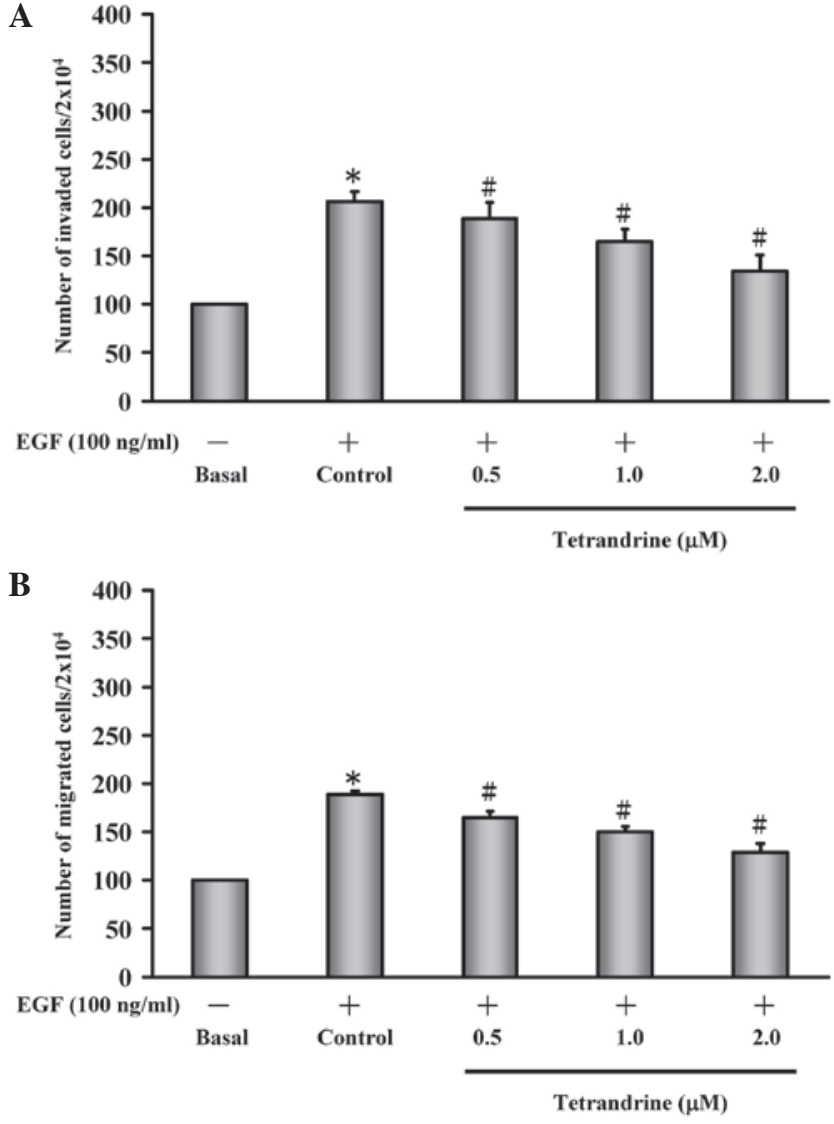

Figure 1. Effects of tetrandrine on the invasion and migration in EGF-induced HT29 human colorectal adenocarcinoma cells. Following 100 ng/ml EGF induction, the cells were seeded in the upper chamber of a Transwell insert and treated with $0.5,1$ or $2 \mu \mathrm{M}$ of tetrandrine for $48 \mathrm{~h}$ to assess (A) cell invasion and (B) migration. Data are expressed on the basis of basal cells representing $100 \%$. The results are expressed as the mean \pm standard deviation of three independent experiments. ${ }^{*} \mathrm{P}<0.05$, vs. basal cells; ${ }^{\#} \mathrm{P}<0.05$, vs. control (EGF only) cells. EGF, epidermal growth factor.

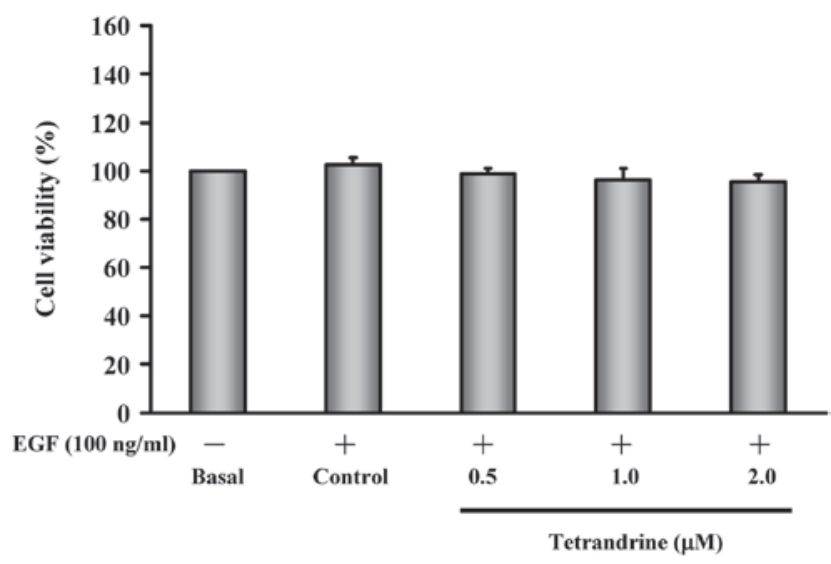

Figure 2. Effects of tetrandrine on HT29 cell viability. The cells were treated with or without $0.5,1$ and $2 \mu \mathrm{M}$ of tetrandrine following treatment with $100 \mathrm{ng} / \mathrm{ml} \mathrm{EGF}$ for $48 \mathrm{~h}$. Cell viability was then determined using a 3-(4,5-dimethyl-2-thiazolyl)-2,5-diphenyl-2H-tetrazolium bromide assay. Data are expressed as the mean \pm standard deviation of three experiments. EGF, epidermal growth factor.

$2 \mu \mathrm{M}$ of tetrandrine, and the gene expression levels of MMP-2 and MMP-9 were determined. The data demonstrated that tetrandrine decreased the mRNA expression levels of MMP-2 

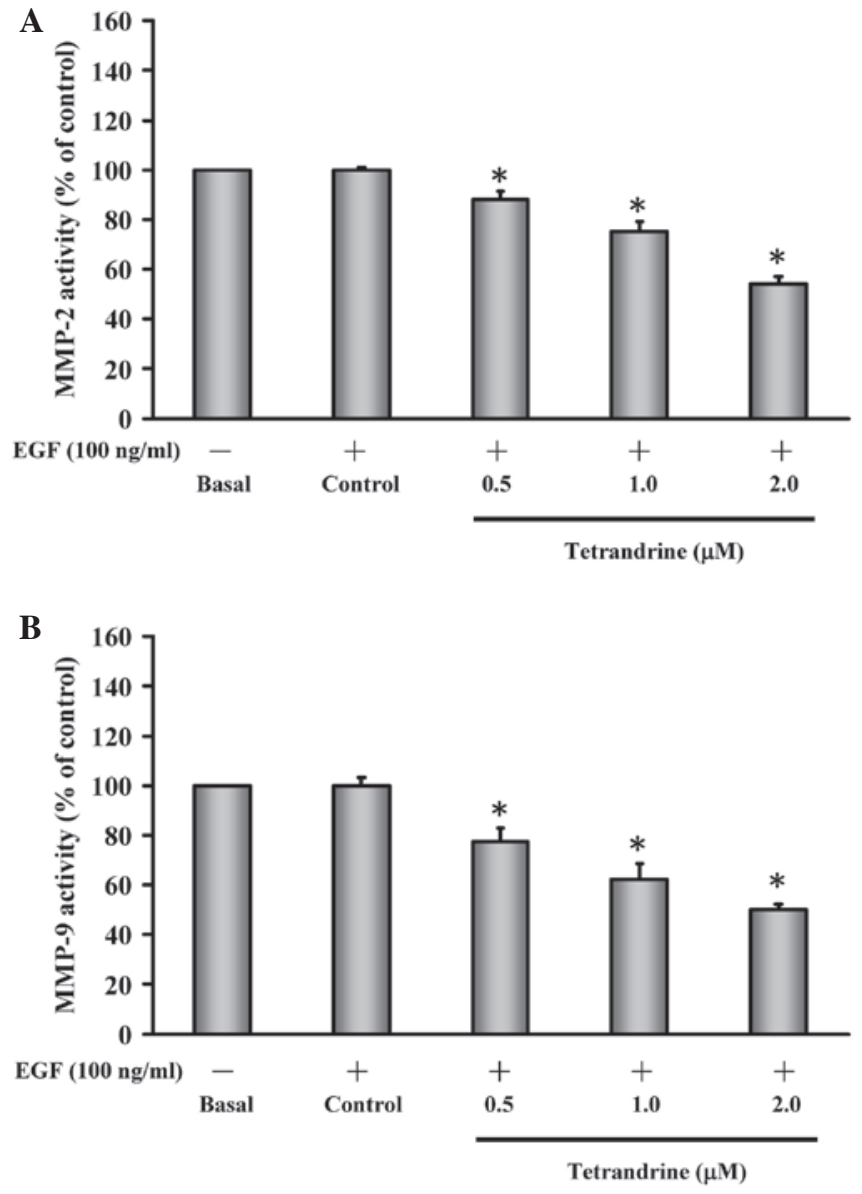

Figure 3. Effects of tetrandrine on the activity of MMP-2 and MMP-9 in EGF-induced HT29 cells. The cells were incubated with or without $0.5,1$ and $2 \mu \mathrm{M}$ of tetrandrine for $48 \mathrm{~h}$ and then subjected to a gelatin zymography assay. Quantitative results of (A) MMP-2 and (B) MMP-9 enzymatic activity were determined and are expressed as the mean \pm standard deviation of three independent experiments. ${ }^{*} \mathrm{P}<0.05$, vs. control (EGF only) cells. MMP, matrix metalloproteinase; EGF, epidermal growth factor.

(Fig. 4A) and MMP-9 (Fig. 4B) in a dose-dependent manner. Based on these findings, it was inferred that the two gelatinases (MMP-2 and MMP-9) contributed to EGF-induced invasion and anti-metastatic effect of HT29 cells.

Tetrandrine inhibits the activation of EGFR. It is well reported that the activation of EGF and its cognate receptor, EGFR, can modulate cell proliferation, survival, invasion and metastasis through activating the autophosphorylation of EGFR and stimulating PI3K/AKT and MAPKs signaling $(2,3)$. In the present study, the effects of tetrandrine on the activation (tyrosine phosphorylation) of EGFR were examined in EGF-induced HT29 cells. Tetrandrine at $0.5,1$ and $2 \mu \mathrm{M}$ led to dose-dependent attenuation of the tyrosine phosphorylation of EGFR on the sites of Y845, Y992 and Y1068 in the treated HT29 cells (Fig. 5). The data indicated that tetrandrine inhibited the activation of EGFR in EGF-induced HT29 cells.

Tetrandrine retards the phosphorylation of PDK1, PI3K and AKT in EGF-induced HT29 cells. To understand the mechanism by which tetrandrine alters the downstream signaling, the present study further examined the PI3K/AKT pathway.
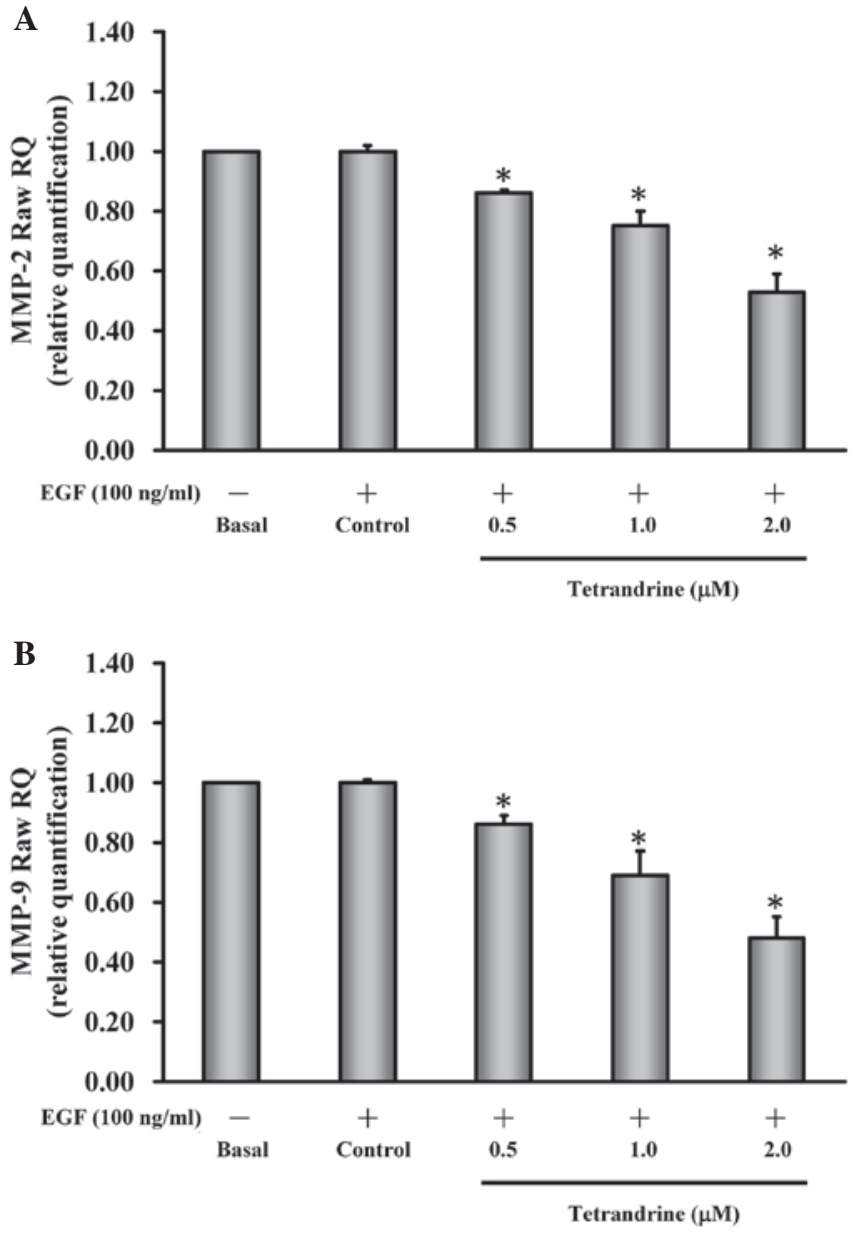

Figure 4. Effects of tetrandrine on the gene expression levels of (A) MMP-2 and (B) MMP-9 in HT29 cells following EGF stimulation. The cells were pre-incubated with $100 \mathrm{ng} / \mathrm{ml}$ EGF and then exposed to $0.5,1$ and $2 \mu \mathrm{M}$ of tetrandrine for $24 \mathrm{~h}$. Reverse transcription-quantitative polymerase chain reaction analysis was performed using specific primers following total RNA purification. All results are expressed as the mean \pm standard deviation of three independent experiments. ${ }^{*} \mathrm{P}<0.05$, vs. control (EGF only) cells. MMP, matrix metalloproteinase; EGF, epidermal growth factor; RQ, relative quantification.

The data demonstrated that tetrandrine $(0.5,1$ and $2 \mu \mathrm{M})$ decreased the protein phosphorylation of PDK1 and PI3K (p85), and reduced the levels of p-AKT on S308 and S473 in the EGF-induced cells (Fig. 6). No effects on the protein levels of PI3K and AKT were observed following tetrandrine challenge. These findings showed that downregulation of EGFR activation caused by tetrandrine treatment was mediated through PI3K/AKT signaling in the EGF-induced HT29 cells.

Tetrandrine affects the MAPK/ERK pathway in EGF-induced $H T 29$ cells. In an attempt to determine the effects of tetrandrine on downstream of EGFR activation, the MAPK (p38, JNK and ERK) pathways were examined in the tetrandrine-exposed cells. Tetrandrine at $0.5,1$ and $2 \mu \mathrm{M}$ reduced the phosphorylation of ERK. However, no effects were observed on the protein expression levels of the p38, JNK and ERK of the MAPK signaling (Fig. 7), indicating that the MAPK/ERK signaling pathway was suppressed by tetrandrine in the EGF-induced HT29 cells. 


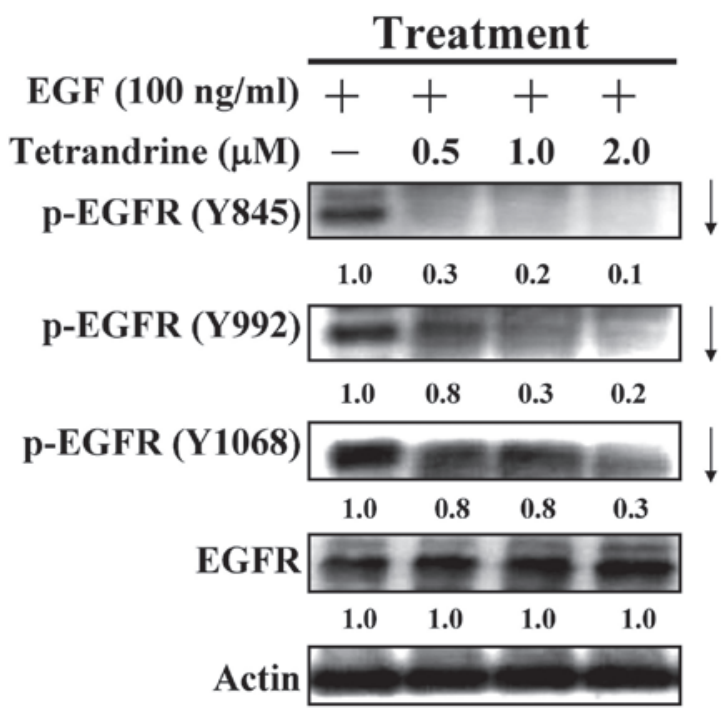

Figure 5. Effects of tetrandrine on EGFR signaling in EGF-induced HT29 cells. Prior to $100 \mathrm{ng} / \mathrm{ml} \mathrm{EGF}$ exposure, the cells were treated with or without $0.5,1$ and $2 \mu \mathrm{M}$ of tetrandrine. After $48 \mathrm{~h}$, the cell lysates were harvested and subjected to western blot analysis. The protein expression levels of p-EGFR (Y845), p-EGFR (Y992), p-EGFR (Y1068) and EGFR were determined and adjusted for equivalent loading using the Actin antibody. EGF, epidermal growth factor; p-EGFR, phosphorylated EGFR.

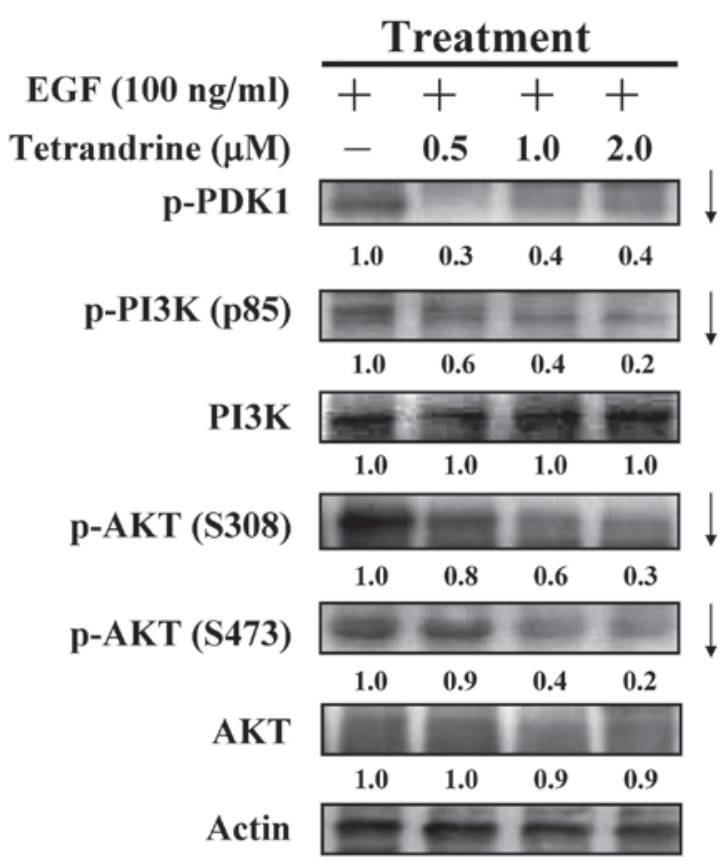

Figure 6. Effects of tetrandrine on the PI3K/AKT pathway in EGF-stimulated HT29 cells. Following stimulation with $100 \mathrm{ng} / \mathrm{ml}$ EGF, the cells were treated with $0.5,1$ and $2 \mu \mathrm{M}$ of tetrandrine for $48 \mathrm{~h}$, and cell lysates were subjected to western blotting for detection of the protein levels of p-PDK1, p-PI3K (p85), PI3K, p-AKT (S308), p-AKT (S473) and AKT. Each band was normalized to Actin. EGF, epidermal growth factor; PI3K, phosphatidylinositol 3-kinase; PDK1, phosphoinositide-dependent kinase 1; p-, phosphorylated.

\section{Discussion}

Colorectal cancer is the third most common cause of cancer-associated mortality $(4,5)$, and selectively targeting the tumor offers a novel strategy for developing novel colorectal

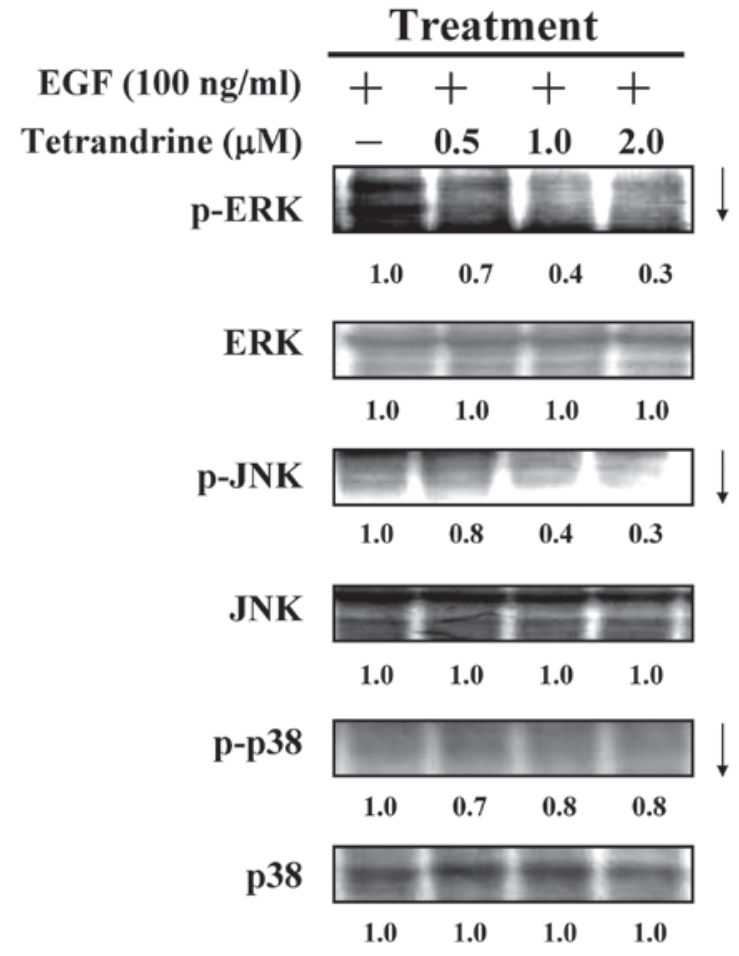

Actin

Figure 7. Effects of tetrandrine on the MAPK pathway in HT29 cells following EGF-induction. The cells, which were pretreated with or without $100 \mathrm{ng} / \mathrm{ml}$ EGF, were treated with $0.5,1$ and $2 \mu \mathrm{M}$ of tetrandrine for $48 \mathrm{~h}$ and lysed prior to immunoblotting. The whole-cell lysates were examined to determine the expression levels of p-ERK, ERK, p-JNK, JNK, p-p38 and $\mathrm{p} 38$. Actin served as an internal control. EGF, epidermal growth factor; MAPK, mitogen-activated protein kinase; JNK, c-Jun N-terminal kinase; p-, phosphorylated.

anticancer agents (15), as the treatment for colorectal cancer remains unsatisfactory. It has been shown that tumor cell apoptosis caused by tetrandrine exhibits inhibitory effects on various types of tumor cell (24-29). The results of the present study indicated that tetrandrine had no cytotoxic effect on the HT29 cells, however, the anti-metastatic effect of tetrandrine on EGF-induced HT29 cancer cells was observed, and the underlying molecular signaling was evaluated. Tetrandrine treatment exerted an inhibitory effect of HT29 cell migration and invasion in the EGF-induced HT29 cells (Fig. 1). Based on these findings, the present study is the first, to the best of our knowledge, to report the effects of tetrandrine on human colorectal cancer cells.

A study by Tsai et al reported that the dysregulation of EGFR was associated with colorectal cancer in Taiwan (41). In addition, the expression levels of EGFR, HER 2 and HER3 were determined in primary tumors of colorectal cancer cells, and corresponded with lymph node metastases and liver metastases $(42,43)$. The dysregulation of human EGFR pathways by the overexpression or constitutive activation promote $s$ tumor processes, angiogenesis and metastasis in several types of human cancer (4-13). Previous studies have demonstrated that tetrandrine inhibits cell metastasis in $4 \mathrm{~T} 1$ breast cancer cells (18) and CT26 colorectal cancer cells in vivo (25). In the latter, tetrandrine-treated $\mathrm{BALB} / \mathrm{c}$ mice were found to exhibit fewer 
metastases, compared with vehicle-treated mice, and no acute toxicity or marked changes in body weight were observed (25). The results of the present study indicated that the EGF-induced invasion of HT29 cells was suppressed by tetrandrine through the inactivation of EGFR and downstream molecules, including suppression of the phosphorylation cascade of PI3K, PDK1 and $\mathrm{AKT}$, and the reduction of p-ERK, which was in agreement with a previous study on lung cancer cells (44).

MMP-2 and MMP-9 are responsible for degradation of the extracellular matrix and facilitating the spread and metastasis of tumor cells in colorectal cancer $(39,40)$. In the present study, tetrandrine suppressed the activities and mRNA expression levels of MMP-2 and MMP-9 in the EGF-induced HT29 cells (Figs. 3 and 4). Therefore, tetrandrine retarded the metastatic effects of EGFR-overexpressed HT29 cells by reducing MMP-2 and MMP-9, and the phosphorylation of EGFR.

The MAPK pathway is a major downstream signaling regulated by EGFR (45). The present study also demonstrated that the levels of p-ERK decreased following tetrandrine treatment in the HT29 cells, which is contradictory to a previous report (46). It has been reported that tetrandrine induces cell autophagy through the activation of MAPK (47). However, the in vitro system in the present study presented the possibility of tetrandrine-triggered autophagy in addition to the suppression of invasion and migration. The data of the present study demonstrated that tetrandrine had inhibitory effects on invasion and mobility in EGF-induced HT29 cells at 1-2 $\mu \mathrm{M}$ (Fig. 1). This evidence suggests that tetrandrine repressed the invasion and metastasis of HT29 cells by activating MAPK and downstream signaling to drive the expression of specific genes. However, it is necessary to be elucidated for the further detailed mechanism in tetrandrine-treated colon cancer cells in vitro.

Taken together, the present study demonstrated that tetrandrine is a promising chemotherapeutic agent with anti-metastatic effects, including the inhibition of migration and invasion, in HT29 human colorectal cancer cells. These findings suggest that tetrandrine may be a potential candidate for the treatment of human colorectal cancer.

\section{References}

1. Segatto O, Anastasi S and Alemá S: Regulation of epidermal growth factor receptor signalling by inducible feedback inhibitors. J Cell Sci 124: 1785-1793, 2011.

2. Lemmon MA, Schlessinger J and Ferguson KM: The EGFR family: Not so prototypical receptor tyrosine kinases. Cold Spring Harb Perspect Biol 6: a020768, 2014.

3. Gibson S, Tu S, Oyer R, Anderson SM and Johnson GL: Epidermal growth factor protects epithelial cells against fas-induced apoptosis. Requirement for akt activation. J Biol Chem 274: 17612-17618, 1999.

4. Augustine TA, Baig M, Sood A, Budagov T, Atzmon G, Mariadason JM, Aparo S, Maitra R and Goel S: Telomere length is a novel predictive biomarker of sensitivity to anti-EGFR therapy in metastatic colorectal cancer. Br J Cancer 112: 313-318, 2015.

5. Möller Y, Siegemund M, Beyes S, Herr R, Lecis D, Delia D, Kontermann R, Brummer T, Pfizenmaier K and Olayioye MA: EGFR-targeted TRAIL and a Smac mimetic synergize to overcome apoptosis resistance in KRAS mutant colorectal cancer cells. PLoS One 9: e107165, 2014.

6. Umeguchi H, Sueoka-Aragane N, Kobayashi N, Nakamura T, Sato A, Takeda Y, Hayashi S, Sueoka E and Kimura S: Usefulness of plasma HGF level for monitoring acquired resistance to EGFR tyrosine kinase inhibitors in non-small cell lung cancer. Oncol Rep 33: 391-396, 2015.
7. Iommelli F, De Rosa V, Gargiulo S, Panico M, Monti M, Greco A, Gramanzini M, Ortosecco G, Fonti R, Brunetti A and Del Vecchio S: Monitoring reversal of MET-mediated resistance to EGFR tyrosine kinase inhibitors in non-small cell lung cancer using 3'-deoxy-3'-[18F]-fluorothymidine positron emission tomography. Clin Cancer Res 20: 4806-4815, 2014.

8. Madden JM, Mueller KL, Bollig-Fischer A, Stemmer P, Mattingly RR and Boerner JL: Abrogating phosphorylation of eIF4B is required for EGFR and mTOR inhibitor synergy in triple-negative breast cancer. Breast Cancer Res Treat 147: 283-293, 2014

9. Jin Y, Han B, Chen J, Wiedemeyer R, Orsulic S, Bose S, Zhang X, Karlan BY, Giuliano AE, Cui Y and Cui X: FOXC1 is a critical mediator of EGFR function in human basal-like breast cancer. Ann Surg Oncol 21 (Suppl 4): S758-S766, 2014.

10. Fung C, Zhou P, Joyce S, Trent K, Yuan JM, Grandis JR, Weissfeld JL, Romkes M, Weeks DE and Egloff AM: Identification of epidermal growth factor receptor (EGFR) genetic variants that modify risk for head and neck squamous cell carcinoma. Cancer Lett 357: 549-556, 2015.

11. Yoshikawa M, Tsuchihashi K, Ishimoto T, Yae T, Motohara T, Sugihara E, Onishi N, Masuko T, Yoshizawa K, Kawashiri S, et al: $\mathrm{xCT}$ inhibition depletes CD44v-expressing tumor cells that are resistant to EGFR-targeted therapy in head and neck squamous cell carcinoma. Cancer Res 73: 1855-1866, 2013.

12. Pan Y, Zheng M, Zhong L, Yang J, Zhou S, Qin Y, Xiang R, Chen Y and Yang SY: A preclinical evaluation of SKLB261, a multikinase inhibitor of EGFR/Src/VEGFR2, as a therapeutic agent against pancreatic cancer. Mol Cancer Ther 14: 407-418, 2015.

13. Mak KS, Gainor JF, Niemierko A, Oh KS, Willers H, Choi NC, Loeffler JS, Sequist LV, Shaw AT and Shih HA: Significance of targeted therapy and genetic alterations in EGFR, ALK, or KRAS on survival in patients with non-small cell lung cancer treated with radiotherapy for brain metastases. Neuro Oncol 17: 296-302, 2015.

14. Wang X, Zuo D, Chen Y, Li W, Liu R, He Y, Ren L, Zhou L, Deng T, Wang X, et al: Shed syndecan-1 is involved in chemotherapy resistance via the EGFR pathway in colorectal cancer. Br J Cancer 111: 1965-1976, 2014.

15. Loupakis F, Cremolini C, Fioravanti A, Orlandi P, Salvatore L, Masi G, Schirripa M, Di Desidero T, Antoniotti C, Canu B, et al: EGFR ligands as pharmacodynamic biomarkers in metastatic colorectal cancer patients treated with cetuximab and irinotecan. Target Oncol 9: 205-214, 2014.

16. Roskoski R Jr: The ErbB/HER family of protein-tyrosine kinases and cancer. Pharmacol Res 79: 34-74, 2014.

17. Miyagawa S, Katsu Y, Watanabe $H$ and Iguchi $T$ : Estrogen-independent activation of erbBs signaling and estrogen receptor alpha in the mouse vagina exposed neonatally to diethylstilbestrol. Oncogene 23: 340-349, 2004.

18. Gao JL, Ji X, He TC, Zhang Q, He K, Zhao Y, Chen SH and Lv GY: Tetrandrine suppresses cancer angiogenesis and metastasis in 4T1 tumor bearing mice. Evid Based Complement Alternat Med 2013: 265061, 2013.

19. Mei L, Chen Y, Wang Z, Wang J, Wan J, Yu C, Liu X and Li W: Synergistic antitumor effects of tetrandrine and chloroquine combination therapy in human cancer: A potential antagonistic role for p21. Br J Pharmacol 172: 2232-2245, 2015.

20. Zhao H, Luo F, Li H, Zhang L, Yi Y and Wan J: Antinociceptive effect of tetrandrine on LPS-induced hyperalgesia via the inhibition of IKK $\beta$ phosphorylation and the COX-2/PGE 2 pathway in mice. PLoS One 9: e94586, 2014.

21. Chang DM, Kuo SY, Lai JH and Chang ML: Effects of anti-rheumatic herbal medicines on cellular adhesion molecules. Ann Rheum Dis 58: 366-371, 1999.

22. Zhang J, Yu B, Zhang XQ, Sheng ZF, Li SJ, Wang ZJ, Cui XY, Cui SY and Zhang YH: Tetrandrine, an antihypertensive alkaloid, improves the sleep state of spontaneously hypertensive rats (SHRs). J Ethnopharmacol 151: 729-732, 2014.

23. Yoo SM, Oh SH, Lee SJ, Lee BW, Ko WG, Moon CK and Lee BH: Inhibition of proliferation and induction of apoptosis by tetrandrine in HepG2 cells. J Ethnopharmacol 81: 225-229, 2002.

24. He BC, Gao JL, Zhang BQ, Luo Q, Shi Q, Kim SH, Huang E, Gao Y, Yang K, Wagner ER, et al: Tetrandrine inhibits Wnt/ $\beta$-catenin signaling and suppresses tumor growth of human colorectal cancer. Mol Pharmacol 79: 211-219, 2011.

25. Chang KH, Liao HF, Chang HH, Chen YY, Yu MC, Chou CJ and Chen YJ: Inhibitory effect of tetrandrine on pulmonary metastases in CT26 colorectal adenocarcinoma-bearing BALB/c mice. Am J Chin Med 32: 863-872, 2004. 
26. Li X, Su B, Liu R, Wu D and He D: Tetrandrine induces apoptosis and triggers caspase cascade in human bladder cancer cells. J Surg Res 166: e45-e51, 2011.

27. Liu W, Zhang J, Ying C, Wang Q, Yan C, Jingyue Y, Zhaocai Y, Yan X, Heng-Jun S and Lin J: Tetrandrine combined with gemcitabine and cisplatin for patients with advanced non-small cell lung cancer improve efficacy. Int J Biomed Sci 8: 28-35, 2012.

28. Chen B, Yin L, Cheng J, Ding J, Gao C, Sun Y, Zhao G, Wang J, Bao W, Xia G, et al: Effect of D, L-threo-1-phenyl-2-decanoylamino-3-morpholino-1-propanol and tetrandrine on the reversion of multidrug resistance in K562/A02 cells. Hematology 16: 24-30, 2011.

29. Wan J, Liu T, Mei L, Li J, Gong K, Yu C and Li W: Synergistic antitumour activity of sorafenib in combination with tetrandrine is mediated by reactive oxygen species (ROS)/akt signaling. $\mathrm{Br}$ J Cancer 109: 342-350, 2013.

30. Liu C, Gong K, Mao X and Li W: Tetrandrine induces apoptosis by activating reactive oxygen species and repressing akt activity in human hepatocellular carcinoma. Int J Cancer 129: 1519-1531, 2011.

31. Huang AC, Lien JC, Lin MW, Yang JS, Wu PP, Chang SJ and Lai TY: Tetrandrine induces cell death in SAS human oral cancer cells through caspase activation-dependent apoptosis and LC3-I and LC3-II activation-dependent autophagy. Int J Oncol 43: 485-494, 2013

32. Wu Z, Wang G, Xu S, Li Y, Tian Y, Niu H, Yuan F, Zhou F, Hao Z, Zheng Y, et al: Effects of tetrandrine on glioma cell malignant phenotype via inhibition of ADAM17. Tumour Biol 35: 2205-2210, 2014.

33. Lai KC, Lu CC, Tang YJ, Chiang JH, Kuo DH, Chen FA, Chen IL and Yang JS: Allyl isothiocyanate inhibits cell metastasis through suppression of the MAPK pathways in epidermal growth factor-stimulated HT29 human colorectal adenocarcinoma cells. Oncol Rep 31: 189-196, 2014.

34. Chen YY, Chiang SY, Lin JG, Ma YS, Liao CL, Weng SW, Lai TY and Chung JG: Emodin, aloe-emodin and rhein inhibit migration and invasion in human tongue cancer SCC-4 cells through the inhibition of gene expression of matrix metalloproteinase-9. Int J Oncol 36: 1113-1120, 2010.

35. Lu CC, Yang JS, Chiang JH, Hour MJ, Amagaya S, Lu KW, Lin JP, Tang NY, Lee TH and Chung JG: Inhibition of invasion and migration by newly synthesized quinazolinone MJ-29 in human oral cancer CAL 27 cells through suppression of MMP-2/9 expression and combined down-regulation of MAPK and aKT signaling. Anticancer Res 32: 2895-2903, 2012.

36. Chen HJ, Lin CM, Lee CY, Shih NC, Amagaya S, Lin YC and Yang JS: Phenethyl isothiocyanate suppresses EGF-stimulated SAS human oral squamous carcinoma cell invasion by targeting EGF receptor signaling. Int J Oncol 43: 629-637, 2013.
37. Lu CC, Yang JS, Chiang JH, Hour MJ, Lin KL, Lee TH and Chung JG: Cell death caused by quinazolinone HMJ-38 challenge in oral carcinoma CAL 27 cells: Dissections of endoplasmic reticulum stress, mitochondrial dysfunction and tumor xenografts. Biochim Biophys Acta 1840: 2310-2320, 2014.

38. Chiang JH, Yang JS, Lu CC, Hour MJ, Chang SJ, Lee TH and Chung JG: Newly synthesized quinazolinone HMJ-38 suppresses angiogenetic responses and triggers human umbilical vein endothelial cell apoptosis through p53-modulated fas/death receptor signaling. Toxicol Appl Pharmacol 269: 150-162, 2013.

39. Peng ZH, Wan DS, Li LR, Chen G, Lu ZH, Wu XJ, Kong LH and Pan ZZ: Expression of COX-2, MMP-2 and VEGF in stage II and III colorectal cancer and the clinical significance. Hepatogastroenterology 58: 369-376, 2011.

40. Deryugina EI and Quigley JP: Matrix metalloproteinases and tumor metastasis. Cancer Metastasis Rev 25: 9-34, 2006.

41. Tsai WC, Lin CK, Lee HS, Chen A, Nieh S, Yu CP, Wu CC, Jao SW and Jin JS: Discordance between EGFR expression and clinicopathologic parameters of colorectal adenocarcinoma in Taiwan. Chin J Physiol 55: 352-360, 2012.

42. Wei Q, Shui Y, Zheng S, Wester K, Nordgren H, Nygren P, Glimelius B and Carlsson J: EGFR, HER2 and HER3 expression in primary colorectal carcinomas and corresponding metastases: Implications for targeted radionuclide therapy. Oncol Rep 25: 3-11, 2011.

43. Rigopoulos DN, Tsiambas E, Lazaris AC, Kavantzas N, Papazachariou I, Kravvaritis C, Tsounis D, Koliopoulou A, Athanasiou AE, Karameris A, et al: Deregulation of EGFR/VEGF/HIF-1a signaling pathway in colon adenocarcinoma based on tissue microarrays analysis. J BUON 15: 107-115, 2010.

44. Wang Y, Liu W and Lin H: Effect and significance of tetrandrine on epidermal growth factor and its receptor in the lung of congenital diaphragmatic hernia rat model. Zhongguo Xiu Fu Chong Jian Wai Ke Za Zhi 20: 1109-1113, 2006 (In Chinese).

45. Nyati MK, Morgan MA, Feng FY and Lawrence TS: Integration of EGFR inhibitors with radiochemotherapy. Nat Rev Cancer 6: 876-885, 2006

46. Dang Y, Xu Y, Wu W, Li W, Sun Y, Yang J, Zhu Y and Zhang C: Tetrandrine suppresses lipopolysaccharide-induced microglial activation by inhibiting NF-kB and ERK signaling pathways in BV2 cells. PLoS One 9: e102522, 2014.

47. Gong K, Chen C, Zhan Y, Chen Y, Huang Z and Li W: Autophagy-relatedgene 7(ATG7)andreactive oxygenspecies/extracellular signal-regulated kinase regulate tetrandrine-induced autophagy in human hepatocellular carcinoma. J Biol Chem 287: 35576-35588, 2012 